\title{
Task Performance Among Employees Above Age 65: The Role of Cognitive Functioning and Job Demand-Control
}

\author{
Andreas Müller ${ }^{1}$, Annet De Lange ${ }^{2,3,4}$, Matthias Weigl ${ }^{5}$, \\ Beatrice Van der Heijden ${ }^{6,7}$, Jorn Ackermans ${ }^{8,9}$, and Julia Wilkenloh ${ }^{10}$
}

\author{
1. Institute for Occupational Medicine and Social Medicine, Medical Faculty, Düsseldorf University, Düsseldorf, Germany \\ 2. Department of Human Resource Management, Faculty of Economics and Management, HAN University of Applied Sciences, Nijmegen, the Netherlands \\ 3. Behavioral Science Institute, Faculty of Psychology, Radboud University Nijmegen, Nijmegen, the Netherlands \\ 4. Norwegian School of Hotel Management, University of Stavanger, Stavanger, Norway \\ 5. Institute and Outpatient Clinic for Occupational, Social, and Environmental Medicine, Ludwig-Maximilians-University Munich, Munich, Germany \\ 6. Institute for Management Research, Radboud University Nijmegen, Nijmegen, the Netherlands \\ 7. Open University of the Netherlands, Heerlen, the Netherlands \\ 8. Department of Work and Organizational Psychology, Radboud University Nijmegen, Nijmegen, the Netherlands \\ 9. Theology, and Religious Studies, Faculty of Philosophy, Radboud University Nijmegen, Nijmegen, the Netherlands \\ 10. Department of Human Resource Studies, Tilburg University, Tilburg, the Netherlands
}

\begin{abstract}
Owing to the aging of Western societies, an increasing number of people over age 65 are now working in bridge employment. Research is needed to understand how job characteristics in bridge employment should be designed to support older employees' productivity, considering potential declines in intra-individual resources. Drawing on lifespan development of resources and job design models, we investigated the interplay of cognitive functioning, job demands, and job control, and their impact on task performance, in a sample of workers in bridge employment. In total, 228 employees from a Dutch temporary employment agency that contracts workers aged 65 years and older participated in this longitudinal study, with a 1-year time lag. Of the panel, $74.1 \%$ of the respondents were male, and the mean age was 69.02 years (range 65-80 years). Cognitive functioning, job demands, job control, and task performance were assessed two times with thoroughly validated self-report measures. Good cognitive functioning emerged as an essential intra-individual resource in order to maintain good task performance for employees aged 65 years and older. After including the influence of job demands and job control, positive effects of cognitive functioning on task performance remained significant only in a high-strain job (with high job demands and low job control). This outcome suggests that age-related changes in cognitive functioning among employees above the age of 65 years only affect productivity at work when the job demands are too high relative to the available job control. Implications for retirement research and lifespan perspectives of job design research are discussed.
\end{abstract}

Due in part to the aging of the population of Western industrialized countries (e.g., Lutz, Sanderson, \& Scherbov, 2008), an increasing number of people above 65 years now work during the period between their retirement decision and complete labor force withdrawal (i.e., they take on bridge employment; e.g., Alcover, Topa, Parry, Fraccaroli, \& Depolo, 2014; Giandrea, Cahill, \& Quinn, 2009; Gobeski \& Beehr, 2009; Kim \& Feldman, 2000; Rudolph, De Lange, \& Van der Heijden, 2015; Shultz, 2003; Shultz \& Wang, 2011; Wang, Zhan, Liu, \& Shultz, 2008; Wang \& Shi, 2014). In the United States, the majority of older employees start full- or part-time bridge employment before exiting the labor force (Giandrea et al., 2009). Older European employees compared to older U.S. employees, however, tend to move directly into full retirement to a higher extent. Nevertheless, both in Europe and in the United States, there is an overall trend that indicates an increase in bridge jobs (Brunello \& Langella, 2012).

From the perspective of adjusting to retirement, bridge employment can be regarded as one of the most central factors for aging individuals to cope with the challenges during retirement transition (Rudolph et al., 2015; Shultz \& Wang, 2011; Wang, Henkens, \& Van Solinge, 2011; Wang \& Shi, 2014; Wang \& Shultz, 2010): Engaging

(c) The Authors 2015. Published by Oxford University Press. For permissions please e-mail: journals.permissions@oup.com Correspondence concerning this article should be addressed to Andreas Müller, Institute for Occupational Medicine and Social Medicine, Medical Faculty, Düsseldorf University, Germany, Universitätsstrasse 1, 40225 Düsseldorf, Germany. E-mail: andreas.mueller@uni-duesseldorf.de 
in bridge employment may promote employee's physical and mental health (Zhan, Wang, Liu, \& Shultz, 2009), retirement satisfaction, and overall life satisfaction (Kim \& Feldman, 2000). For working organizations, bridge employment is beneficial because it helps to retain access to the valuable experience that older employees have gained throughout their professional careers, especially during skilled workforce shortages (Alcover et al., 2014; Shultz \&Wang, 2011; Wang \& Shultz, 2010). From a societal perspective, labor market participation through older age is extremely important because it will relieve the burden on social security and pension systems as older employees continue to contribute. Therefore, further investigation is needed to better understand how we can enhance the added value of employees above age 65 during this stage of the retirement process.

Considering the official retirement age ( 65 years, or slightly above in most European countries), employees are likely to enter bridge employment at an age when decrements of age-sensitive domains of cognitive functioning — such as maintaining information in working memory, or detecting information quickly-might become more relevant (e.g., Schaie, 1994). Moreover, bridge employment frequently involves a change in occupation, industry, or both (e.g., Cahill, Giandrea, \& Quinn, 2011). Thus, bridge jobs might not be mastered successfully by drawing mainly on previous job experiences, which typically would help to equalize decrements in cognitive functioning (Baltes, 1997). Bridge jobs might therefore demand a rather considerable level of age-sensitive domains of cognitive functioning because the latter are requirements for learning new routines and skills at work (Kanfer \& Ackerman, 2004). In sum, bridge employment can accentuate the discrepancy between age-related losses and challenging contextual job characteristics.

Against this background, the present study was guided by the key question: "How should job characteristics in bridge employment be designed in order to guarantee that employees above age 65 are able to remain productive, given potential, relative losses in cognitive functioning?"

Our study draws on the theoretical perspective of lifespan development, with an emphasis on gains and losses of resources (Baltes, 1997; Hobfoll \& Wells, 1998), and on psychosocial models of job design, such as the Job Demand-Resources Model (JD-R, Demerouti, Bakker, Nachreiner, \& Schaufeli, 2001), and the job demand-control model (JD-C, Karasek, 1979). From a lifespan development perspective, an aging individual faces dwindling intra-individual resources (e.g., cognitive functioning) that successively outweigh gains of resources (e.g., experience; Baltes, 1997). According to the conservation of resources theory (COR, Hobfoll \& Wells, 1998), contextual job characteristics either catalyze or counteract the detrimental impact of these intra-individual resource losses on functioning, personal development, and wellbeing over a lifespan (Westman, Hobfoll, Chen, Davidson, \& Laski, 2005). The JD-R model allows for the distinction between those contextual job characteristics that are expected to either amplify or counteract the consequences of intra-individual resource losses. According to the JD-R model, job demands are defined as job characteristics that require physiological and psychological energy from the employee, whereas contextual job resources are defined as job characteristics that support employees in accomplishing job tasks, that directly reduce job demands, or that stimulate resource growth (Demerouti et al., 2001). Consequently, available intra-individual resources of older employees are expected to be more important for favorable intra-individual outcomes when job demands are high and contextual job resources are low (e.g., Rudolph et al., 2015).

Building upon these considerations, our approach was specifically inspired by the proposition of the theoretical framework on adult development at the workplace, developed by Kanfer and Ackerman (2004), which proposes that the interplay between age-sensitive domains of cognitive functioning and job demands predicts the performance of older employees at work. According to Borman and Motowidlo (1997; see also Ng \& Feldman, 2008), we define performance in terms of good core task performance, that is "the effectiveness with which job incumbents perform activities that contribute to the organization's technical core," (p. 99). Transferring the framework by Kanfer and Ackerman to bridge employment, we asked ourselves two questions: "Is cognitive functioning a relevant intra-individual resource for older employees in bridge employment to maintain a sufficient level of task performance?" and "Do higher job demands amplify the expected positive effects of cognitive functioning on task performance in older employees in bridge employment?" To further extend the perspective of our study, we additionally incorporated job control as one of the most important contextual job resources, according to the JD-R model (Demerouti et al., 2001) and the JD-C model (Karasek, 1979). Job control is defined as the extent to which a job allows freedom, independence, and discretion to schedule work, make decisions, and choose the methods used to perform tasks (Morgeson \& Humphrey, 2006). Specifically, we investigated the question: "Does job control buffer the expected positive impact of cognitive functioning on task performance in older employees who are exposed to high job demands?" In their lifespan theory of control, Heckhausen and Schulz (1995) postulated that individuals have a basic need to possess control over their environment. Accordingly, job control repeatedly has been shown to facilitate positive work experiences, intrinsic motivation, and enhanced performance outcomes (e.g., De Lange, Taris, Kompier, Houtman, \& Bongers, 2003; Humphrey, Nahrgang, \& Morgeson, 2007). In particular, in respect to older employees, studies have reported that increased job control helps to counterbalance resource losses (Van den Berg, Robroek, Plat, Koopmanschap, \& Burdorf, 2011; Weigl, Müller, Hornung, Zacher, \& Angerer, 2013).

Our study addresses several gaps in the scholarly literature: Taking the view that bridge employment itself might be an indicator of adjustment to retirement (Shultz \& Wang, 2011; Wang et al., 2011; Wang \& Shi, 2014; Wang \& Shultz, 2010); previous literature on retirement that incorporated job characteristics mainly addressed the question of how pre-retirement jobs affect retirement decisions, such as taking on bridge employment (e.g., Elovainio et al., 2005; Gobeski \& Beehr, 2009; Gørtz, 2012; Wang et al., 2008; Wöhrmann, Deller, \& Wang, 2013). In a similar vein, the literature on the interplay between cognitive functioning and job characteristics during retirement transition also focused exclusively on the question of whether preretirement job characteristics moderate the change in cognitive functioning both before and after retirement (Finkel, Andel, Gatz, \& Pedersen, 2009; Fisher et al., 2014). Little attention has been devoted to the question of how postretirement job design might support older employees, who already are in bridge employment, to remain productive despite potential losses in cognitive functioning (Rudolph et al., 2015). The same is true regarding the lifespan perspective of job design (e.g., Schlick, Frieling, \& Wegge, 2013; Truxillo, Cadiz, Rineer, Zaniboni, \& Fraccaroli, 2012; Truxillo \& Fraccaroli, 2013). Until now, only a few empirical studies 
have examined how to design jobs for older employees, taking into account normal age-related changes in intra-individual resources, such as cognitive functioning. Moreover, we do not know much about how changes in cognitive functioning above age 65 affect the productivity of employees. Previous research on adult cognitive development has been mainly based on laboratory experiments that test cognitive limits (e.g., Salthouse, 2013), yet applied field research on this issue is still lacking. Therefore, the practical relevance of findings regarding age-related cognitive declines for the work context remains a matter of debate (Kanfer \& Ackerman, 2004).

We addressed the limitations from previous scholarly work by conducting a longitudinal study among 228 Dutch employees above age 65 who were engaged in bridge employment. Our longitudinal approach, with a focus on the interplay between cognitive functioning, job demands, and job control on task performance, enabled us to gain new insights into the adjustment process during bridge employment. Experiencing good performance has been shown to strengthen personal self-efficacy, and vice versa (Lindsley, Brass, \& Thomas, 1995). Along that vein, the positive experience of sustained performance in bridge employment is expected to have a strong personal meaning for older employees in respect to their future positive adjustment to critical transitions during retirement (Rudolph et al., 2015). Additionally, as our study used a sample that is rather homogeneous in terms of chronological age (i.e., the number of years lived) and, likewise, heterogeneous in terms of cognitive functioning, we were able to disentangle the effects of intra-individual age-related changes in cognitive functioning from the effects of chronological age on productivity during later career stages (Ng \& Feldman, 2008).

\section{Hypotheses Development}

Cognitive functioning and task performance in bridge employment From a resources perspective (cf. Hobfoll \& Wells, 1998), work and organizational psychologists highlighted the impact of cognitive functioning as one of the major intra-individual resources of older employees which allows them to remain productive at work (Kanfer \& Ackerman, 2004). Longitudinal studies showed quite consistently that those aspects of cognitive functioning that are summarized under the term fluid intellectual abilities (Cattell, 1987), such as the capability of working memory or perceptual speed, tend to decline over one's lifespan (e.g., Salthouse, 2013; Schaie, 1994). Notwithstanding the fact that aging is not a uniform process, and inferences from chronological age to cognitive functioning are at risk for bias (e.g., Morse, 1993; Schaie \& Hofer, 2001), it is likely that healthy individuals in their midsixties are at an enhanced risk for decline and deterioration in cognitive functioning (e.g., Schaie, 1994).

From an occupational point of view, the question arises regarding whether these age-related cognitive decrements might impair task performance in employees aged 65 years and older (Kanfer \& Ackerman, 2004). Many jobs do not make demands on the outermost limits of cognitive functioning. Hence, with the exception of highly demanding cognitive jobs, such as air traffic controller (e.g., Müller, Petru, Englmann, \& Angerer, 2011), a decrease in, for example, perceptual speed within the range of milliseconds does not pose serious problems for the job performance of older employees $(\mathrm{Ng} \&$ Feldman, 2008; Warr, 1993). Additionally, older employees might be able to compensate for declines because they accumulated job-specific experience during their career (e.g., Baltes, 1997). For example,
Salthouse (1984) investigated the speed and accuracy of keystrokes among typists ranging in age from 19 to 72 years. One interesting finding was that older typists could compensate for a slower reaction time because they were more sensitive in characters farther in advance. Thus, in many jobs, age-related declines of fluid intellectual abilities can be compensated for by the age-related increase of socalled crystallized intellectual abilities, such as experience and expertize (Cattell, 1987). Therefore, in jobs that do not pose exceeding levels of age-critical job demands, healthy and successful aging is usually signified by-and associated with-enhanced task performance (Kanfer \& Ackerman, 2004).

Bridge jobs, however, may represent a specific case that suggests the need for a closer examination of the impact of cognitive functioning on task performance. As already stated, employees are likely to enter bridge employment at an age in which decrements in cognitive functioning might become more relevant (Schaie, 1994). Additionally, bridge jobs are likely to be novel jobs for the aged jobholders (Cahill et al., 2011). Thus, in contrast to most other jobs, we expect a weaker supporting effect of accumulated job experience that usually buffers age-related declines in older employees (e.g., Baltes, 1997). Moreover, increased cognitive functioning in terms of fluid intellectual abilities boosts quick and successful adaptation through learning and mastery, which is expected to be a strong predictor of performance on the job (Kanfer \& Ackerman, 2004). As a result, we assume that good cognitive functioning is a predictor of better task performance in a bridge employment sample.

H1: There is a lagged, positive relationship between cognitive functioning and task performance in older employees in bridge employment.

\section{The interplay between cognitive functioning, job demand-control, and task performance}

Consistent with the COR perspective of interacting intra-individual resources and contextual job characteristics (Westman et al., 2005), and building upon previous considerations (Kanfer \& Ackerman, 2004), we assume that job demands in bridge employment impact the strength of the association between cognitive functioning and task performance of employees above age 65 . As explained above, bridge jobs are often novel jobs that cannot exclusively be accomplished through prior experience and routines that older employees usually have accumulated during their professional careers. Thus, job demands in bridge employment are expected to pose rather high demands on cognitive functioning in terms of the fluid intellectual abilities of older employees, in order to learn necessary routines and skills for performing successfully. Consequently, it is not simply the quantity of job demands in bridge employment that is expected to be relevant, but rather the inherent quality of novelty in job demands (Kanfer \& Ackerman, 2004). Thus, we expect that cognitive functioning has a stronger positive impact on task performance for older employees with high job demands in bridge employment compared to older employees in bridge employment with low job demands.

H2: Job demands moderate the lagged positive association between cognitive functioning and task performance in 
older employees in bridge employment, such that there is a stronger association under high job demands compared to low job demands.

Consistent with the JD-C model (Karasek, 1979), we further assume that the interaction between job demands and job control affects the strength of the lagged relationship between cognitive functioning and task performance. The JD-C model proposes four possible combinations of high/low job demands and high/low job control: (a) highstrain jobs, (b) active jobs, (c) passive jobs, and (d) low-strain jobs. These four types are important combinations of job characteristics because they signify entirely different regulatory demands on the employee (Karasek, 1979).

High-strain jobs (combining high job demands and low job control) are jobs with a high risk for stress and poor health experiences (e.g., De Lange et al., 2003). Consistent with the resources perspective (Hobfoll \& Wells, 1998), we assume that high-strain jobs, on the one hand, put high demands on the older employee, but, on the other hand, provide only limited possibilities to apply effective individual strategies that would allow for the compensation of intra-individual agerelated declines (Van den Berg et al., 2011). This perspective is in line with very recent theoretical considerations regarding the adjustment to bridge employment, which have suggested that intra-individual resources are more important when there is an imbalance in terms of low contextual job resources and high job demands, and, correspondingly, when people are less likely to rely on intra-individual resources as contextual job resources meet job demands (Rudolph et al., 2015). We therefore assume that in high-strain jobs, cognitive functioning is most crucial for task performance compared to other kinds of job demand-control types, especially because such high-strain jobs impose on the employee the most unfavorable combination of high regulatory demands and low job control possibilities (Hacker, 2003).

Like high-strain jobs, active jobs are also characterized by high job demands, but at the same time, provide high job control. Again, from a resources and adjustment perspective, we can expect that job control in active jobs contributes to the maintenance and growth of professional capacity in older employees. Maintenance should be enhanced because, contrary to high-strain jobs, active jobs allow older employees to apply behavioral strategies to compensate for diminished cognitive functioning and to effectively cope with high job demands (Weigl et al., 2013). One of the few available studies that put the JD-C model into the lifespan perspectives of job design was conducted by Shultz, Wang, Crimmins, and Fisher (2010). Their findings, using a representative European sample of working adults, indicated that older employees appear to be particularly in need of job control to reduce the experience of stress from job demands. The authors interpret this outcome considering potential cognitive declines, such that job control might allow older employees, for instance, to schedule cognitively demanding tasks during times when distractions are minimized, in order to compensate for declines in cognitive inhibition. Moreover, active jobs should support growth because they are expected to lead to an increase in learning and problem-solving activities (De Lange et al., 2010; De Witte, Verhofstadt, \& Omey, 2007; Taris \& Kompier, 2004), and therefore allow for the acquirement of new routines to better meet the respective demands of bridge jobs in the future. Thus, in respect to our research question, we assume that in active jobs, cognitive functioning of employees above age 65 in bridge employment is positively related to task performance because active jobs pose high demands. However, we assume that the association between cognitive functioning and task performance in active jobs is weaker than in high-strain jobs. This is because the job control available in active jobs should allow for the compensation of age-related declines and adoption of new behavioral routines.

In contrast to job demand-control combinations that impose high job demands, we do not assume that job control affects the relationship between cognitive functioning and task performance in jobs with low demands; that is, passive jobs (low job demands and low job control) and low-strain jobs (low job demands and high job control). According to our previously described rationale, the degree of cognitive functioning is expected to be less important for task performance when job demands are low. Along the same vein, the similar supporting effects of job control are expected to be weaker. Thus, for older employees in passive and low-strain jobs, there are only minor needs to compensate for age-related declines or to learn new routines.

To sum up our last hypotheses, we assume that the combination of job demands and job control moderates the lagged relationship between cognitive functioning and task performance of employees above age 65 in bridge employment. Additionally, we expect that job control affects the relationship between cognitive functioning and task performance in jobs that encompass high job demands, such that effects of cognitive functioning are strongest in jobs that contain high job demands and low job control (high-strain jobs) compared to other job demand-control types.

H3: The combination of job demands and job control moderates the lagged positive association between cognitive functioning and task performance in older employees in bridge employment.

H3a: The lagged positive association between cognitive functioning and task performance in older employees in bridge employment is stronger in high-strain jobs compared to other job demand-control types (active, passive, and low-strain jobs).

H3b: The lagged positive association between cognitive functioning and task performance in older employees in bridge employment is stronger in active jobs compared to passive and low-strain jobs.

\section{METHOD}

\section{Sample}

Data for the present study were part of a larger two-wave panel study conducted in 2011 and 2012 in the Netherlands (as part of the European Union). Wave one of this study took place in May, 2011. Initially, all registered clients of a temporary employment agency that specifically contracts workers older than age 65 were invited to participate $\left(N=6,538 ; 74.80 \%\right.$ males, $M_{\text {age }}=69.70$ years $)$. Of the invited workers, $n=784$ active workers responded to an online questionnaire (response rate $=11.99 \%$ ). In May, 2012, a follow-up wave of data was collected. Again, all registered clients of the same employment agency were invited to participate. Of the invited workers, $n=655$ completed the online questionnaire at Time 2 (response rate $=10.01 \%$ ). Considering both time points ( $\mathrm{T} 1$ and $\mathrm{T} 2), n=228$ respondents 
completed both waves, and these individuals constitute the panel considered here. In all, $74.1 \%$ of this panel's respondents were male, with a mean age of 69.02 years ( $S D=3.08$ years; range $65-80$ years). The largest part had a bridge employment position in the education and science sector (32\%), followed by transportation and delivery (19.7\%), and office work (18\%). Of our sample, $14.2 \%$ reported that they currently did not work actively at the time of the first or the second wave. On average, the respondents had worked 5.33 years $(S D=9.30)$ in their current positions. The median tenure was three years (i.e., $61 \%$ of the employees worked three years or less in their current role). Thus, for the majority of employees in this sample, the bridge job was a new job compared to their previous employment, which is in line with the typical feature of bridge jobs.

\section{Survey Measures}

\section{Cognitive functioning}

Cognitive functioning was measured with the Cognitive Failures Questionnaire (CFQ; Broadbent, Cooper, Fitzgerald, \& Parkes, 1982). The 25 items cover attentional, memory, and action failures in everyday tasks that persons can normally execute successfully (e.g., "Do you fail to notice signposts on the road?"; "Do you find you forget people's names?”). This well-established scale has proved to be a highly reliable and valid measure of cognitive functioning that involves attention, memory, and action in daily life in a healthy working population (Bridger, Johnsen, \& Brasher, 2013). All items used a 5-point Likert-type scale. Higher values indicate better cognitive functioning. Cronbach's alpha was .92 and .92 at T1 and T2, respectively.

\section{Task performance}

Task performance was assessed with three items of the scale proposed by Van der Heijde and Van der Heijden (2006): "During the past year, I was, in general, competent to perform my work accurately and with few mistakes"; "Overall, how do you see yourself in terms of your work performance?"; "What proportion of your work would you say you brought to a successful conclusion in the past year?" All items used a six-point Likert-type scale. Higher values indicate better task performance. Cronbach's alpha was .67 and .79 at T1 and T2, respectively.

\section{Job demands and job control}

Job demands and job control were measured with the respective scales of the well-established Job Content Questionnaire by Karasek et al. (1998). Job demands were assessed with five items (e.g., "My job requires working very fast"). Job control was assessed with three items specifically covering decision authority (e.g., "My job allows me to make a lot of decisions on my own"). All items were scored using a fourpoint Likert-type scale. Higher values indicate higher job demands or higher job control, respectively. Cronbach's alpha was .50/.52, for the job demands-scale, and .76/.78 for job control-scale.

\section{Control variables}

To account for potential influence of employees' sociodemographic characteristics on our study variables of interest, we included information on respondents' chronological age, gender, and job tenure (cf., $\mathrm{Ng}$ $\&$ Feldman, 2008). Moreover, we controlled working status by means of a dichotomous variable $(0=$ no work at $\mathrm{T} 1$ or $\mathrm{T} 2 ; 1=$ work at $\mathrm{T} 1$ and $\mathrm{T} 2)$ if the employees were actively working at each of the two waves.

\section{Analyses}

Our analyses used structural equation modeling (SEM) with the statistical package "lavaan (0.5-14)" (Rosseel, 2012), implemented in the software environment for statistical computing and graphics " $R$ " (R Development Core Team, 2013). We used maximum likelihood estimation and applied conventional cut-offs (e.g., Brown, 2006; Byrne, 2001) of accepted goodness-of-fit indices to estimate model fit: Incremental fit indices (CFI, TLI, IFI) should be $>.90$, indicating good fit, whereas RMSEA below <.08 would indicate reasonable fit, and $<.05$ would indicate good fit. Moreover, we report the $90 \%$ confidence interval and $p$-value for the tests where RMSEA exceeds .05.

\section{RESULTS}

\section{Job Types}

To assess jobs with high and low job demands and jobs characterized by the four job demand-control types, we first averaged the degree of job demands and job control, respectively, across the two measurements. This aggregation is justified for the following reasons: $82 \%$ of the employees reported no change of their bridge job during the study period in terms of changes of employer, function, or task. Those employees who did experience a change in one of those aspects did not report a significant modification in the degree of job demands and job control within the 1-year period from $\mathrm{T} 1$ to $\mathrm{T} 2$.

In accordance with common practice to capture the job types proposed by the JD-C model, in the second step, we conducted a median split of the aggregated job demand and the aggregated job control values (e.g., De Lange, Taris, Kompier, Houtman, \& Bongers, 2002). Employees below the job demand median reported an average job demand of $M=2.01(S D=.23)$, whereas employees above the median reported an average job demand of $M=2.63(S D=.23)$. Members of both groups did not significantly differ regarding the reported level of job control $(M=2.92 ; S D=.62$ vs. $M=2.94 ; S D=.57)$. Employees below the job control median reported an average job control of $M=2.44(S D=.34)$, whereas employees above the median reported an average job control of $M=3.41(S D=.34)$. Members of the low and the high job control group did not differ significantly regarding job demands $(M=2.28 ; S D=.38$ vs. $M=2.35 ; S D=.39)$. Thus, on the basis of the meaning of the four-point scale assessing job demands and job control (see the Methods' section), the group means allowed for a meaningful interpretation in terms of high/low job demands and high/low job control.

Consequently, we established four groups representing the jobdemand control types as proposed by Karasek (1979) through the combination of job demands and job control above and below the median. High-strain jobs represented the combination of high job demands above the median and low job control below the median. Accordingly, active jobs combined high job demands and high job control; low-strain jobs combined low job demands and high job control; and passive jobs combined low job demands and low job control. The group with high-strain jobs contained $n=52$ persons (active jobs contained $n=59$; low-strain jobs contained $n=57$; and passive jobs contained $n=60$ ).

\section{Measurement Models}

We subjected the two instruments assessing cognitive functioning and task performance to confirmatory factor analysis (CFA) in the 
following steps to ensure that the items represented psychometrically distinguishable constructs. In line with recommendations of Little, Cunningham, Shahar, and Widaman (2002), we used five-item parcels in the CFA instead of the 25 individual CFQ items in order to sustain a reasonable ratio of degrees of freedom and sample size. To warrant balanced parceling, we first selected the five CFQ items with the highest factor loadings to anchor the parcels; afterwards, we added the five items with the next highest loadings in inverted order, and so forth.

Next, we compared the fit of the hypothesized two-factor model, distinguishing between the latent factors cognitive functioning and task performance, with a one common-factor model. We did this separately for the two waves (Table 1: Model 1a vs. Model 1b; Model 2a vs. Model 2b). Results show that at T1 and T2, the hypothesized two-factor model showed an overall good fit and was significantly superior to the common-factor model. Subsequently, we estimated the measurement invariance across the two waves by combining the hypothesized two-factor model at T1 and T2 into one model with four correlated factors. Consistent with common practice, measurement errors of the same indicators were correlated across waves to account for their non-independence (e.g., Brown, 2006). We sequentially added constraints to the model, starting with equal factor loadings of the same indicators, followed by additional equal factor variances of the same factors, and finally ending with equal covariances between same pairs of factors (e.g., Byrne, 2001). Although the added constraints resulted in a significant decrease of fit, compared to the unconstrained model (compare Model 3c-3d vs. Model 3a in Table 1), all of the constrained models still showed good or reasonable fit. Thus, variables seemed to have stable meanings across the waves.

\section{Descriptive Statistics and Group Comparisons}

Table 2 summarizes the means and standard deviations of the two focal variables cognitive functioning and task performance. Mean values show that the older employees, on average, reported good cognitive functioning and good task performance for the two measurements, respectively. ANCOVA revealed that employees with high and low job demands did not statistically differ regarding cognitive functioning and task performance at $\mathrm{T} 1$ and $\mathrm{T} 2$, respectively. With the exception of cognitive functioning at $\mathrm{T} 2$, the two focal variables also did not appear to differ across the four job demand-control types at both time points. Post hoc tests showed that at T2, bridge employees in active jobs reported significantly higher cognitive functioning than did bridge employees in high-strain jobs $(p<.05)$, as well as employees with passive jobs $(p<.01)$. Despite this difference, our data indicate that a strong self-selection bias - in the sense that older employees in this sample selected the type of bridge job regarding their level of cognitive functioning - is implausible.

\section{Path Models}

Consistent with the two-step SEM approach proposed by Anderson and Gerbing (1988), we used the scale means of each variable to test our hypotheses (i.e., cognitive functioning at $\mathrm{T} 1$ is the mean of all cognitive functioning items at $\mathrm{T} 1$ ). We started with a stability model with solely auto-regression paths of cognitive functioning and task performance. Moreover, this model included regression paths of the control variables age, gender, job tenure, and working status at T2 measures of cognitive functioning and task performance (Table 3: Model A). The model provided good incremental fit compared to an independence model (indicated by CFI, TLI, and IFI) and reasonable absolute fit to the data (indicated by the RMSEA; Table 3). All auto-regression effects were strong and highly significant: The effect from cognitive functioning T1 to cognitive functioning T2 was $\beta=.79(p<.001)$; for task performance it was $\beta=.55(p<.001)$. Of all the control variables, only working status showed a significant effect on the T2 measure of cognitive functioning $(\beta=.11, p<.01)$, indicating that working actively was positively related with better cognitive functioning at follow-up.

In order to test Hypothesis 1 (better cognitive functioning predicts better task performance), we added the direct lagged effect from cognitive functioning at $\mathrm{T} 1$ to task performance at $\mathrm{T} 2$ to the auto regression paths of the stability model (Table 3: Model B). This causal effect model provided good incremental fit according to CFI, TLI, and IFI, and good absolute fit according to the RMSEA. Additionally, it achieved a superior fit to the data compared to the stability model. Higher cognitive functioning at $\mathrm{T} 1$ significantly predicted better task performance at T2 $(\beta=.16 ; p<.01)$, supporting Hypothesis 1 (Table 4 ).

Table 1. Fit Statistics of Measurement Models

\begin{tabular}{|c|c|c|c|c|c|c|c|c|c|}
\hline Model Description & $\chi^{2}$ & $d f$ & CFI & TLI & IFI & RMSEA [CI] & & $\Delta \chi^{2}$ & $\Delta d f$ \\
\hline 1a. Common factor (T1) & 109.53 & 20 & .91 & .87 & .91 & $.140[.115-.166]^{* * *}$ & & & \\
\hline $\begin{array}{l}\text { 1b. Two factors: cognitive functioning, task performance } \\
\text { (T1) }\end{array}$ & 20.55 & 19 & 1.00 & 1.00 & 1.00 & $.019[.000-.062] n s$ & $1 \mathrm{~b}$ vs.1a & $88.98^{* * *}$ & 1 \\
\hline 2a. Common factor (T2) & 212.42 & 20 & .82 & .76 & .81 & $.205[.181-.231]^{* * *}$ & & & \\
\hline $\begin{array}{l}\text { 2b. Two factors: cognitive functioning, task performance } \\
\text { (T2) }\end{array}$ & 38.74 & 19 & .98 & .97 & .98 & $.069[.038-.099] n s$ & $2 \mathrm{~b}$ vs. $2 \mathrm{a}$ & $173.68^{* * *}$ & 1 \\
\hline 3a. Four factors: unconstrained & 125.38 & 90 & .99 & .99 & .99 & $.042[.022-.058] n s$ & & & \\
\hline 3b. Four factors: equal factor loadings across time & 147.44 & 96 & .98 & .98 & .98 & $.048[.032-.064] n s$ & $3 \mathrm{~b}$ vs. $3 \mathrm{a}$ & $22.06^{* * *}$ & 6 \\
\hline $\begin{array}{l}\text { 3c. Four factors: equal factor loadings, variances across } \\
\text { time }\end{array}$ & 162.39 & 98 & .98 & .97 & .98 & $.054[.039-.068] n s$ & $3 \mathrm{c}$ vs. $3 \mathrm{~b}$ & $37.01^{* * *}$ & 2 \\
\hline $\begin{array}{l}\text { 3d. Four factors: equal factor loadings, variances, } \\
\text { covariances across time }\end{array}$ & 162.67 & 99 & .98 & .97 & .98 & $.053[.038-.067] n s$ & $3 d$ vs. $3 c$ & $37.29^{* * *}$ & 1 \\
\hline
\end{tabular}

Note CFI = comparative fit index CI = 90\% confidence interval; TLI = Tucker-Lewis index; ILI = Incremental Fit Index; RMSEA = root-mean-square error of approximation.

${ }^{* * *} p<.001 ;{ }^{* *} p<.01 ;{ }^{*} p<.05$. 
Table 2. Means (M) and Standard Deviations $(S D)$ of Cognitive Functioning and Task Performance, and Results of Mean Difference Tests, (ANCOVA) Across Job Demand-Control Types

\begin{tabular}{|c|c|c|c|c|c|c|c|c|c|c|c|c|c|}
\hline & \multirow{2}{*}{$\begin{array}{l}\text { Total } \\
n=228\end{array}$} & \multicolumn{2}{|l|}{ Job Demands } & \multirow[t]{3}{*}{$F$} & \multirow[t]{3}{*}{$d f$} & \multirow[t]{3}{*}{$p$} & \multicolumn{4}{|c|}{$\begin{array}{l}\text { Job Types According to Job Demand-Control } \\
\text { Model }\end{array}$} & \multirow[t]{3}{*}{$F$} & & \multirow[t]{3}{*}{$p$} \\
\hline & & Low, $n=126$ & $\begin{array}{l}\text { High, } \\
n=102\end{array}$ & & & & $\begin{array}{l}\text { High-Strain } \\
\text { Jobs, } n=52\end{array}$ & $\begin{array}{l}\text { Active Jobs, } \\
n=59\end{array}$ & $\begin{array}{l}\text { Low-strain } \\
\text { Jobs, } n=57\end{array}$ & $\begin{array}{l}\text { Passive } \\
\text { Jobs, } \\
n=60\end{array}$ & & & \\
\hline & $M(S D)$ & $M(S D)$ & $M(S D)$ & & & & $M(S D)$ & $M(S D)$ & $M(S D)$ & $M(S D)$ & & & \\
\hline $\begin{array}{l}\text { Cognitive functioning } \\
\text { (T1) }\end{array}$ & $4.02(.44)$ & $3.95(.43)$ & $4.09(.44)$ & 1.50 & 1 & .22 & $3.92(.48)$ & $4.18(.40)$ & $4.01(.46)$ & $3.92(.37)$ & 1.64 & 3 & .18 \\
\hline $\begin{array}{l}\text { Cognitive functioning } \\
\text { (T2) }\end{array}$ & $4.00(.44)$ & $3.99(.41)$ & $4.06(.48)$ & 2.39 & 1 & .12 & $3.95(.45)$ & $4.15(.47)$ & $4.02(.42)$ & $3.96(.40)$ & 2.94 & 3 & .03 \\
\hline $\begin{array}{l}\text { Task Performance } \\
\qquad(\mathrm{T} 1)\end{array}$ & $5.07(.51)$ & $5.03(.52)$ & $5.12(.48)$ & 1.97 & 1 & .16 & $5.04(.52)$ & $5.15(.44)$ & $5.17(.44)$ & $4.92(.58)$ & 1.87 & 3 & .14 \\
\hline $\begin{array}{l}\text { Task performance } \\
\qquad(\mathrm{T} 2)\end{array}$ & $5.04(.59)$ & $5.01(.63)$ & $5.09(.54)$ & 1.2 & 1 & .27 & $5.03(.57)$ & $5.11(.54)$ & $5.01(.65)$ & $5.02(.59)$ & .56 & 3 & .64 \\
\hline
\end{tabular}

Note. $\mathrm{T} 1$ = baseline. $\mathrm{T} 2$ = follow-up. ANCOVA results adjusted for age, gender, tenure.

Subsequently, to test Hypothesis 2, we compared the causal effects between cognitive functioning and task performance for older employees with high job demands on the one hand, and older employees with low job demands on the other hand. The respective multiple group model exhibited a good fit (Table 3: Model C). Consistent to Hypothesis 2, cognitive functioning at $\mathrm{T} 1$ showed a significant, positive effect on task performance at T2 under high job demands, whereas there was no such significant association under low job demands. In order to test for the significance of this difference, we compared the fit of an unconstrained Model C and the fit of a constrained Model $\mathrm{C} 1$ that assumed equally lagged effects of cognitive functioning at $\mathrm{T} 1$ on task performance at $\mathrm{T} 2$ in both groups. This additional constraint in Model C1 led to a significant decrease of the model fit (Table 3: Model C1 vs. Model C), corroborating the assumption that the lagged effects of cognitive functioning on task performance differ significantly between older employees with high job demands compared to those with low job demands.

Hypothesis 3 predicted that the combination of job demands and job control moderates the lagged relationship between cognitive functioning and task performance. We therefore compared the causal effect models for four groups of employees that reported high-strain, active, low-strain, and passive jobs in terms of the JDC model. The unconstrained multiple group model (Model D) exhibited a good fit (Table 3), whereas the constrained multiple group model (Model D1) - with equally fixed lagged effects of cognitive functioning on task performance across groups - fit significantly worse (although the overall model fit was still good). Thus, Hypothesis 3 was confirmed by these data. The differential effects of cognitive functioning at T1 on task performance at $\mathrm{T} 2$ over the four job types are listed in Table 4. In accordance with our assumptions, among all job types, cognitive functioning showed the strongest lagged association with job performance in high-strain jobs. In active jobs, we observed the second strongest association between cognitive functioning and task performance. However, in all other remaining job-demand control types except high-strain jobs, this association was statistically insignificant. An unexpected finding was the insignificant auto-regression of task performance in the group with high-strain jobs, pointing to a destabilization of task performance in older employees under such unfavorable working conditions.

In order to further confirm Hypothesis 3a, which stated that the lagged effect between cognitive functioning and task performance is stronger in high-strain jobs compared to other job demand-control types, we compared the effects of employees with high-strain jobs to a second group that included all the remaining types of employees. Again, we tested an unconstrained model (Model E) against a constrained model with equally fixed lagged causal effects of cognitive functioning on task performance (Model E1). The constrained model had a significantly lower fit compared to the unconstrained model (Table 3), supporting Hypothesis 3 a.

Finally, in a similar way we compared the group active jobs to a second group that included the employees with passive or low-strain jobs. This was conducted to test Hypothesis $3 \mathrm{~b}$, which assumed that in active jobs, there is a stronger lagged association between cognitive functioning and task performance, compared to passive and low-strain jobs. Also, here, the constrained model (Model F1) had a significantly lower fit compared to the unconstrained model (Model F2, cf. Table 3), confirming Hypothesis $3 \mathrm{~b}$.

\section{DISCUSSION}

As earlier research on adjustment processes in bridge employment did not empirically investigated the interplay between psychosocial job characteristics, cognitive functioning, and task performance among older workers, this study tested these relations in a new two-wave complete panel study. From the perspective of adult lifespan development of resources (Baltes, 1997; Hobfoll \& Wells, 1998; Kanfer \& Ackerman, 2004) and job design models, and in particular, the JD-C model (Karasek, 1979), we formulated several theory-based hypotheses. After testing our hypotheses, it was revealed that: (a) increased cognitive functioning predicts better task performance; (b) the lagged positive effects of cognitive functioning on task performance are stronger under high job demands compared to low job demands; and (c) the combination of job demands and job control moderates the 
Table 3. Fit Statistics of Structural Models

\begin{tabular}{|c|c|c|c|c|c|c|c|c|c|}
\hline Model description & $x^{2}$ & $d f$ & CFI & TLI & IFI & RMSEA $[\mathrm{CI}]$ & & $\Delta \chi^{2}$ & $\Delta d f$ \\
\hline Model A: Stability model & 18.64 & 10 & .97 & .94 & .97 & $.067[.010-.113] n s$ & & & \\
\hline Model B: Causal effect model & 11.81 & 9 & .99 & .98 & .99 & $.040[.000-.095] n s$ & B vs. A & $6.83^{* * *}$ & 1 \\
\hline $\begin{array}{l}\text { Model C: Causal effect model: high vs. low job } \\
\text { demands }\end{array}$ & 23.86 & 22 & .99 & .98 & .99 & $.029[.000-.091] n s$ & & & \\
\hline $\begin{array}{l}\text { Model C1: Causal effect model: high vs. low job } \\
\text { demands (constrained) }\end{array}$ & 35.80 & 24 & .96 & .91 & .96 & $.071[.000-.117] n s$ & C1 vs. C & $11.94^{* * *}$ & 2 \\
\hline $\begin{array}{l}\text { Model D: Causal effect model: job demand-control } \\
\text { types }\end{array}$ & 35.59 & 36 & 1.00 & 1.00 & 1.00 & $.000[.000-.101] n s$ & & & \\
\hline $\begin{array}{l}\text { Model D1: Causal effect model: job demand-control } \\
\text { types (constrained) }\end{array}$ & 47.68 & 40 & .97 & .94 & .98 & $.063[.000-.122] n s$ & D1 vs. D & $12.09^{*}$ & 4 \\
\hline $\begin{array}{l}\text { Model E: Causal effect model: high-strain jobs vs. } \\
\text { else }\end{array}$ & 16.83 & 18 & 1.00 & 1.01 & 1.00 & $.000[.000-.084] n s$ & & & \\
\hline $\begin{array}{l}\text { Model E1: Causal effect model: high-strain jobs vs. } \\
\text { else (constrained) }\end{array}$ & 28.49 & 20 & .97 & .94 & .97 & $.066[.000-.117] n s$ & E1 vs. E & $11.66^{* *}$ & 2 \\
\hline Model F: Causal effect model: active jobs vs. else & 13.79 & 18 & 1.00 & 1.04 & 1.02 & $.000[.000-.075] n s$ & & & \\
\hline $\begin{array}{l}\text { Model F1: Causal effect model: active jobs vs. else } \\
\text { (constrained) }\end{array}$ & 24.95 & 20 & .98 & .95 & .98 & $.057[.000-.120] n s$ & F1 vs. F & $11.16^{* *}$ & 2 \\
\hline
\end{tabular}

Note CFI = comparative fit index; CI = 90\% confidence interval; TLI = Tucker-Lewis index; ILI = Incremental Fit Index; RMSEA = root-mean-square error of approximation.

${ }^{* * *} p<.001{ }^{* *} p<.01 ;{ }^{*} p<.05$.

Table 4. Autoregression-Coefficients and Effects of Cognitive Functioning on Task Performance in Different Combinations of Job Demands and Job Control

\begin{tabular}{|c|c|c|c|}
\hline & $\begin{array}{l}\text { Autoregression Cognitive Functioning } \\
(\mathrm{T} 1, \mathrm{~T} 2)\end{array}$ & $\begin{array}{l}\text { Autoregression Task } \\
\text { Performance }(\mathrm{T} 1, \mathrm{~T} 2)\end{array}$ & $\begin{array}{l}\text { Cognitive Functioning (T1) on Task } \\
\text { Performance (T2) }\end{array}$ \\
\hline Model & $\beta$ & $\beta$ & $\beta$ \\
\hline \multicolumn{4}{|l|}{ Model B } \\
\hline Total sample & $.79^{* * *}$ & $.49^{* * *}$ & $.16^{* *}$ \\
\hline \multicolumn{4}{|l|}{ Model C } \\
\hline Low demands & $.80^{* * *}$ & $.59^{* * *}$ & .09 \\
\hline High demands & $.75^{* * *}$ & $.36^{* * *}$ & $.22^{*}$ \\
\hline \multicolumn{4}{|l|}{ Model D } \\
\hline High-strain job & $.76^{* * *}$ & .25 & $.27^{*}$ \\
\hline Active job & $.80^{* * *}$ & $.43^{* * *}$ & .20 \\
\hline Low-strain job & $.79^{* * *}$ & $.55^{* * *}$ & .08 \\
\hline Passive job & $.81^{* * *}$ & $.61^{* * *}$ & .10 \\
\hline
\end{tabular}

Note. $\mathrm{T} 1$ = baseline. $\mathrm{T} 2$ = follow-up.

${ }^{* * *} p<.001 ;{ }^{* *} p<.01 ;{ }^{*} p<.05$.

lagged positive effects of cognitive functioning on task performance, such that cognitive functioning has the strongest positive effect on task performance when job demands are high and job control is low, and the weakest effects when job demands are low, regardless of the level of job control.

The first two findings support one of the main assumptions of the theoretical framework on adult development in the workplace. Kanfer and Ackerman (2004) stated that cognitive functioning in terms of "fluid intellectual abilities" is an essential resource for maintaining productivity in late careers, when job demands require senior employees to learn new routines and skills. Our second finding that the combination of job demands and job control moderates the lagged positive effects of cognitive functioning on task performance further extends the framework of Kanfer and Ackerman by the inclusion of contextual job resources (e.g., Demerouti et al., 2001). Altogether, the observed buffering effect of job control on the relationship between cognitive functioning and task performance under high job demands can be interpreted in light of recent findings that apply the perspective of adaptive lifespan strategies in terms of selection, optimization, and compensation (SOC; P. B. Baltes \& Baltes, 1990). These findings suggest that job control enables the effective use of such adaptive strategies that, in turn, allow for the balancing of potential intra-individual age-related in older employees (Müller, Weigl, Heiden, Glaser, \& Angerer, 2012; Weigl et al., 2013). The specific single effects on the interplay between cognitive functioning, job demands, and job control can be explained by Karasek's (1979) established J-DC model: 
As hypothesized, jobs with high job demands and low job control (i.e., high-strain jobs) seem to require extraordinary regulatory effort from older employees (Shultz et al., 2010; Van den Berg et al., 2011). Therefore, in high-strain jobs, task performance depends strongly on cognitive functioning. The insignificant auto-regression of task performance in employees above age 65 with high-strain jobs was unexpected. According to the notion that sustainable employability in older age is not solely a matter of dynamic adjustment but also predicated on maintenance and stability (Rudolph et al., 2015), this observed destabilization of task performance further indicates the detrimental effects of high-strain jobs for employees above age 65 .

An important finding of this study is that, on the same high level of job demands, task performance seems to be less affected by cognitive functioning under high job control (active jobs). The message behind this finding is that employees above age 65 in bridge employment can maintain productivity in demanding jobs if they have ample control over their job (i.e., when their job allows for sufficient discretion to organize the work according to their individual needs; see also Van den Berg et al., 2011). Nevertheless, we observed that task performance in active jobs tends to depend on cognitive functioning. However, referring to Karasek's (1979) learning hypothesis that active learning in the workplace will occur when high job demands are combined with high job control (De Lange et al., 2010; De Witte et al., 2007), we would expect that in the long-run, older employees in active jobs are able to acquire new job routines that increasingly relieve the load on their agesensitive fluid intellectual abilities.

The finding that the weakest effects of cognitive functioning on task performance emerged in jobs with low job demands and high job control (low-strain jobs) and in jobs with low job demands and low job control (passive jobs) does not necessarily imply that these two kinds of jobs best meet the requirements of age-adequate job design. Passive jobs are expected to especially induce boredom and monotony (Reijseger et al., 2013), with increased risks for depression-related behavioral styles, such as learned helplessness (Karasek, 1979).

In sum, our findings suggest that in order to maintain the productivity of older employees above age 65 in bridge employment, age-adequate job design should provide a high level of contextual job resources in terms of job control rather than solely decrease the level of job demands.

\section{Theoretical Implications of the Study}

Our longitudinal investigation contributes novel findings to the research on retirement adjustment (Rudolph et al., 2015; Wang \& Shi, 2014; Wang et al., 2011). The study specifically highlights the benefits of good working conditions for the successful adjustment to bridge employment; an issue that was largely ignored in previous scholarly work. By demonstrating that job characteristics can also be essential during later stages of the retirement process, our approach may further contribute to gaining a more comprehensive perspective on the dynamics of retirement adjustment over time.

Along the same vein, our study meets essential research challenges in regard to lifespan perspectives of job design (Schlick et al., 2013; Truxillo \& Fraccaroli, 2013; Truxillo et al., 2012). We conducted one of the few studies that demonstrated that the JD-C model (Karasek, 1979) can be meaningfully applied beyond stress research; specifically, it can be applied to lifespan perspectives on job design (De Lange et al, 2010; Shultz et al., 2010; Van den Berg et al., 2011). Our study especially contributes to the growing evidence that job control represents a valuable contextual job resource for older employees in their compensation for potential age-related declines and incapacities (Müller et al., 2012; Shultz et al., 2010; Van den Berg et al., 2011; Weigl et al., 2013). Furthermore, our study extends previous findings on the supporting effects of job control to the under-researched population of employees above age 65, which is expected to become increasingly vulnerable to cognitive declines (Schaie, 1994). Moreover, as our research disentangles the effects of intra-individual age-related changes from the effects of chronological age, it further specifies previous findings on age differences concerning JD-C (De Lange et al, 2010; Shultz et al., 2010). This latter approach is very important because members of older age groups tend to have a greater variance in individual characteristics (e.g., cognitive functioning) than members of younger age groups (Morse, 1993). Consequently, chronological age can be regarded as a less reliable predictor of productivity in older compared to younger age cohorts. With that in mind, our construct and operationalization complies with the call to use broader age operationalizations in research by a growing number of scholars, who suggest that functional capacity is a more relevant criterion for the productivity of older employees than is chronological age alone (De Lange et al., 2006; Schalk et al., 2010).

\section{Practical Implications of the Study}

By demonstrating that cognitive functioning is an important intraindividual resource for the productivity of employees above age 65, our study suggest that sustainable human resource management practices should necessarily aim to enhance the cognitive functioning of employees from the beginning of their careers. With enhanced cognitive functioning, age-related declines will start from a higher level and should therefore impair productivity much later in life (M. M. Baltes \& Lang, 1997). For this purpose, good job design that includes adequate job demands and high job control can contribute to a fruitful learning culture (De Lange et al., 2010), and therefore prevent cognitive decline (Fisher et al., 2014).

By further demonstrating that high job control buffers the impact of cognitive functioning on task performance in highly demanding jobs, our study indicates that sustainable human resource management should meet older employees' need to autonomously schedule their work or to choose the specific methods to perform their tasks (Shultz et al., 2010; Van den Berg et al., 2011; Weigl et al., 2013). This will enable older employees to cope effectively with age-related cognitive declines and is expected to sustainably maintain their productivity over their entire careers.

\section{Limitations and Future Research}

Our study has several limitations. First, all data have been collected using questionnaires opening up the possibility of response set consistencies. Thus, the question arises as to whether the constructs used have been measured reliably. Available research provides evidence that the CFQ used is considerably correlated with objective indices of cognitive functioning (Manly, Robertson, Galloway, \& Hawkins, 1999). However, in one recent study by Harty, O'Connell, Hester, and Robertson (2013), older adults underestimated their difficulties with attentional control and memory functioning using the CFQ. Thus, it is possible that our study provides an estimation of cognitive functioning in employees above age 65 that is too liberal. Similarly, measuring task performance with self-reports is a strong limitation of this study. For 
example, the relationship between chronological age and performance seems to vary with the source of performance measurement, although self-reports do not necessarily inflate associations ( $\mathrm{Ng} \&$ Feldman, 2008). This may have affected our observations of the cognitive functioning and performance relationships. Beyond that, the exclusive use of self-reports opens up the possibility of common-method bias (Podsakoff, MacKenzie, Lee, \& Podsakoff, 2003). However, our extensive confirmatory factor analyses clearly indicated that the measures and questionnaire items used represented distinguishable constructs. Moreover, altogether, there is only limited empirical evidence suggesting that common methods inflate associations between variables to a significant degree (Spector, 2006). Nevertheless, future studies should apply objective performance measures of cognitive functioning and use multiple sources of performance measurement to safeguard our findings.

Second, this study used only a rough estimation of job demands. Moreover, in accordance with findings reported by the developers of the Job Content Questionnaire (Karasek et al., 1998), the internal consistency of the job demands scale was rather low, indicating that the instrument involves a considerable amount of measurement error. Nonetheless, many earlier studies were based on this Dutch survey measure and revealed a sufficient internal consistency score (e.g., De Lange et al., 2010). Nevertheless, future studies should apply alternative measures that explicitly capture age-sensitive cognitive job demands, such as quick information processing, intense working memory demands, or solving novel problems. This may provide a more reliable and valid test of the hypothesis that job demands especially require fluid intellectual abilities to accentuate the association between cognitive functioning and task performance in older employees in bridge employment (Kanfer \& Ackerman, 2004).

Third, the specific characteristics of our sample might restrict, to some extent, both the internal and external validity of our findings: The employees in our sample shared the same employer (i.e., the temporary employment agency), but were engaged in different jobs at different work places. Therefore, it could be argued that it is ambiguous whether these self-reports are valid for the employment situation or for the job task. However, as all our focal work-related variables (job demands, job control, and task performance) clearly refer to the job task, such a bias is unlikely in our study. Further, the study includes participants that did not actively work at the time of the two surveys. Thus, their reports about job characteristics and task performance might be prone to recall bias. Although we adjusted our results for working status, this fact limits the interpretability of our findings.

Fourth, we used median split for the outcomes of the quantitative variables in order to establish the four job demand-control types. This procedure includes several methodological limitations, such as loss of information or biased estimation of effect sizes (e.g., MacCallum, Zhang, Preacher, \& Rucker, 2002). However, we believe that in our case, this approach is acceptable because it is consistent with theory (Karasek, 1979), and additionally, the median represented meaningful cut-offs.

Fifth, with regard to external validity, as most employees in our sample reported rather low job tenure, our findings cannot be generalized without further consideration to employees in career bridge employment who have worked in the same industry or field as before retirement (Wang et al., 2008). In other words, in employees in career bridge employment, age-sensitive domains of cognitive functioning might be less important for productivity because accumulated job experience helps offset decrements. Also, our findings cannot be generalized to other countries and cultures because it draws exclusively on a Dutch sample. From the perspective of career development, many researchers have argued for the need to incorporate cultural context in terms of values and identity, etc. (Fouad \& Arbona, 1994). Furthermore, we assume that in countries with different pension or retirement legislations, the nature of jobs that are held by bridge employees may potentially be different (Alcover et al., 2014). Moreover, although our sample was representative for the population of employees of the cooperating agency, in terms of age and gender the response rate of the first survey was rather low. Thus, future investigations that are based on representative samples of bridge employees and, ideally, use longitudinal cohort designs, are needed to investigate the extent to which our findings generalize to other contexts.

Sixth, as previously mentioned, our results suggest that job design affects individual adjustment strategies, which, in turn, help to compensate for potential age-related declines in cognitive functioning. Yet, our present design restricts us from inferring about the role of such strategies. Thus, future studies may aim to reveal intra-individual adjustment processes more explicitly by additionally incorporating important theories of lifespan development, such as the SOC model (P. B. Baltes \& Baltes, 1990), and the lifespan theory of control (Heckhausen \& Schulz, 1995). For instance, recent investigations tested three-way interactions between job characteristics, chronological age, and the application of SOC behavior (Weigl et al., 2013; Zacher \& Frese, 2011). These studies showed that SOC behavior support older employees to cope successfully with job demands (Zacher \& Frese, 2011), and that job control fosters the efficient application of SOC in senior employees (Weigl et al., 2013). Along with recent lifespan developmental frameworks, a SOC perspective is expected to benefit retirement research because it would, for example, help to better understand the reorganization of the work of older employees in retirement (Löckenhoff, 2012).

To summarize, from the broader perspective of COR theory (Hobfoll \& Wells, 1998), there seems to be a meaningful interaction between intra-individual resources (such as cognitive functioning), job demands, and contextual job resources, and the efficient use of intra-individual resources in terms of adjustment processes for favorable work-related outcomes. This dynamic lifespan resource perspective might guide future research endeavors regarding age-adequate job design (Truxillo et al., 2012), retirement adjustment (Löckenhoff, 2012), and adjustment to bridge employment specifically (Rudolph et al., 2015).

Finally, our study is restricted to single organizational aspects of bridge employment, neglecting multifarious influences at the societal level, such as social welfare systems and labor markets. As an example, beside voluntary bridge employment, many retirees might be forced to continue working and to accept disadvantageous working conditions in bridge employment in order to supplement inadequate retirement incomes later in life (e.g., Cahill, Giandrea, \& Quinn, 2006; Taylor \& Geldhauser, 2007; Topa, Moriano, Depolo, Alcover, \& Moreno, 2011). This might particularly affect women. Because of the discontinuity of working careers and gender income gaps, many women approach retirement with reduced savings and lower pensions (e.g., Zaidi, 2010). Our sample, with predominantly male, white collar workers was not able to appropriately cover these critical issues. Thus, more 
research is needed that focuses on bridge employment of older female employees with a lower social status, low financial resources, or a lower level of skills.

\section{CONCLUSION}

Our study demonstrates that normal age-related changes in cognitive functioning for employees above age 65 do not necessarily have to affect productivity. Given this outcome, our findings may stimulate human resource management practices that aim to establish sustainability at work (i.e., to sustain employees' health and working capacity over their lifespan; De Lange, Kooij, \& Van der Heijden, 2015). Moreover, our results demonstrate that the design of healthy or decent jobs (with e.g., job autonomy) is an important preventative HR instrument for successful aging at work.

\section{ACKNOWLEDGMENTS}

The authors would like to thank Anastasia Byler for native speaker support.

\section{REFERENCES}

Alcover, C.-M., Topa, G., Parry, E., Fraccaroli, F., \& Depolo, M. (2014). Bridge employment. Lessons learned and future prospects for research and practice. In C.-M. Alcover, G. Topa, E. Parry, F. Fraccaroli, \& M. Depolo (Eds.), Bridge employment: A research handbook (pp. 269-290). London: Routledge.

Anderson, J. C., \& Gerbing, D. W. (1988). Structural equation modeling in practice: A review and recommended two-step approach. Psychological Bulletin, 103, 411-423.

Baltes, P. B. (1997). On the incomplete architecture of human ontogeny: Selection, optimization, and compensation as foundation of developmental theory. American Psychologist, 52, 366-380.

Baltes, P. B., \& Baltes, M. M. (1990). Psychological perspectives on successful aging: The model of selective optimization with compensation. In P. B. Baltes, \& M. M. Baltes (Eds.), Successful aging: Perspectives from the behavioral sciences (pp. 1-34). New York, NY: Cambridge University Press.

Baltes, M. M., \& Lang, F. R. (1997). Everyday fuctioning and successful aging. The impact of resources. Psychology and Aging, 12, 433-443.

Borman, W. C., \& Motowidlo, S. J. (1997). Task performance and contextual performance: The meaning for personnel selection research. Human Performance, 10, 99-109.

Bridger, R. S., Johnsen, S. A. K., \& Brasher, K. (2013). Psychometric properties of the Cognitive Failures Questionnaire. Ergonomics, 56, 1515-1524.

Broadbent, D. E., Cooper, P. F., Fitzgerald, P., \& Parkes, K. R. (1982). The Cognitive Failures Questionnaire (CFQ) and its correlates. British Journal of Clinical Psychology, 21, 1-16.

Brown, T. (2006). Confirmatory factor analysis for applied research. New York, NY: Guilford Press.

Brunello, G., \& Langella, M. (2012). Bridge jobs in Europe. Discussion Paper No. 6938, Bonn, Germany: Institute for the Study of Labor.

Byrne, B. M. (2001). Structural equation modeling with AMOS. Mahwah, NJ: Lawrence Earlbaum Associates.

Cahill, K. E., Giandrea, M. D., \& Quinn, J. F. (2006). Down shifting: The role of bridge jobs after career employment. Issue brief 06. Chestnut Hill, MA: The Center on Aging and Work, Boston College.
Cahill, K. E., Giandrea, M. D., \& Quinn, J. F. (2011). How does occupational status impact bridge job prevalence? (BLS working paper 447). Washington, DC: Bureau of Labor Statistics.

Cattell, R. B. (1987). Intelligence: Its structure, growth, and action. Amsterdam, the Netherlands: North-Holland.

De Lange, A. H., Kooij, T. A. M., \& van der Heijden, B. I. J. M. (2015). Human resource management and sustainability at work across the lifespan: An integrative perspective. In Finkelstein, D., Truxillo, D., Fraccaroli, F., \& Kanfer, R. (Eds.), Facing the challenges of a multi-age workforce. A use-inspired approach. New York, NY: Taylor \& Francis.

De Lange, A. H., Taris, T. W., Jansen, P. G. W., Kompier, M. A. J., Houtman, I. L. D., \& Bongers, P. M. (2010). On the relationships among work characteristics and learning-related behavior: Does age matter? Journal of Organizational Behavior, 31, 925-950.

De Lange, A. H., Taris, T. W., Jansen, P. G. W., Smulder, P., Houtman, I. L. D., \& Kompier, M. A. J. (2006). Age as a factor in the relation between work and mental health: Results from the longitudinal TAS survey. In J. Houdmont, \& S. McIntyre (Eds.), Occupational health psychology: European perspectives on research, education and practice (pp. 21-45). Maia, Portugal: ISMAI Publications.

De Lange, A. H., Taris, T. W., Kompier, M. A., Houtman, I. L. D., \& Bongers, P. M. (2002). The effects of stable and changing demandcontrol histories on worker health: Results of the longitudinal SMASH study. Scandinavian Journal of Work, Environment, and Health, 28, 94-108.

De Lange, A. H., Taris, T. W., Kompier, M. A., Houtman, I. L. D., \& Bongers, P. M. (2003). The very best of the millenium: Longitudinal research and the demand-control-(support) model. Journal of Occupational Health Psychology, 8, 282-305.

Demerouti, E., Bakker, A. B., Nachreiner, F., \& Schaufeli, W. B. (2001). The job demands-resources model of burnout. Journal of Applied Psychology, 56, 499-512.

De Witte, H., Verhofstadt, E., \& Omey, E. (2007). Testing Karasek's learning and strain hypotheses on young workers in their first job. Work \& Stress, 21, 131-141.

Elovainio, M., Forma, P., Kivimäki, M., Sinervo, T., Sutinen, R., \& Laine, M. (2005). Job demands and job control as correlates of early retirement thoughts in Finnish social and health care employees. Work \& Stress, 19, 84-92.

Finkel, D., Andel, R., Gatz, M., \& Pedersen, N. L. (2009). The role of occupational complexity in trajectories of cognitive aging before and after retirement. Psychology and Aging, 24, 563-573.

Fisher, G. G., Stachowski, A., Infurna, F. J., Faul, J. D., Grosch, J., \& Tetrick, L. E. (2014). Mental work demands, retirement, and longitudinal trajectories of cognitive functioning. Journal of Occupational Health Psychology, 19, 231-242.

Fouad, N. A., \& Arbona, C. (1994). Careers in a cultural context. The Career Development Quarterly, 43, 96-112.

Giandrea, M. D., Cahill, K. E., \& Quinn, J. F. (2009). Bridge jobs: A comparison across cohorts. Research on Aging, 31, 549-576.

Gobeski, K. T., \& Beehr, T. A. (2009). How retirees work: Predictors of different types of bridge employment. Journal of Organizational Behavior, 30, 401-425.

Gørtz, M. (2012). Early retirement in the day-care sector: The role of working conditions and health. European Journal of Aging, 9, 187-198. 
Hacker, W. (2003). Action regulation theory-A practical tool for the design of modern work processes. European Journal of Work and Organization Psychology, 12, 105-130.

Harty, S., O’Connell, R. G., Hester, R., \& Robertson, I. H. (2013). Older adults have diminished awareness of errors in the laboratory and daily life. Psychology and Aging, 28, 1032-1041.

Heckhausen, J., \& Schulz, R. (1995). A life-span theory of control. Psychological Review, 102, 284-304.

Hobfoll, S. E., \& Wells, J. D. (1998). Conservation of resources, stress, and aging: Why do some slide and some spring? In J. Lomranz (Ed.). Handbook of aging and mental health: An integrative approach (pp. 121-134). New York, NY: Plenum Press.

Humphrey, S. E., Nahrgang, J. D., \& Morgeson, F. P. (2007). Integrating motivational, social, and contextual work design features: A metaanalytic summary and theoretical extension of the work design literature. Journal of Applied Psychology, 92, 1332-1356.

Kanfer, R., \& Ackerman, P. L. (2004). Aging, adult development, and work motivation. Academy of Management Review, 29, 440-458.

Karasek, R. A. (1979). Job demands, job decision latitude and mental strain: Implications for job redesign. Administrative Science Quarterly, 24, 285-308.

Karasek, R. A., Brisson, C., Kawakami, N., Houtman, I., Bongers, P., \& Amick, B. (1998). The Job Content Questionnaire (JCQ): An instrument for internationally comparative assessments of psychosocial job characteristics. Journal of Occupational Health Psychology, 3, 322-355.

Kim, S., \& Feldman, D. C. (2000). Working in retirement: The antecedents of bridge employment and its consequences for quality of life in retirement. Academy of Management Journal, 43, 1195-1210.

Lindsley, D. H., Brass, D. J., \& Thomas, J. B. (1995). Efficacy-performing spirals: A multilevel perspective. Academy of Management Review, 20, 645-678.

Little, T. D., Cunningham, W. A., Shahar, G., \& Widaman, K. F. (2002). To parcel or not to paarcel: Exploring the question, weighing the merits. Structural Equation Modeling: A Multidisciplinary Journal, 9, 151-173.

Löckenhoff, C. E. (2012). Understanding retirement: The promise of life-span developmental frameworks. European Journal of Aging, 9, 227-231.

Lutz, L., Sanderson, W., \& Scherbov, S. (2008). The coming acceleration of global population ageing. Nature, 451, 716-719.

MacCallum, R. C., Zhang, S., Preacher, K. J., \& Rucker, D. D. (2002). On the practice of dichotomization of quantitative variables. Psychological Methods, 7, 19-40.

Manly, T., Robertson, I. H., Galloway, M., \& Hawkins, K. (1999). The absent mind: Further investigations of sustained attention to response. Neuropsychologia, 37, 661-670.

Morgeson, F. P., \& Humphrey, S. E. (2006). The Work Design Questionnaire (WDQ): Developing and validating a comprehensive measure for assessing job design and the nature of work. Journal of Applied Psychology, 91, 1321-1339.

Morse, C. K. (1993). Does variability increase with age? An archival study of cognitive measures. Psychology and Aging, 8, 156-164.

Müller, A., Petru, R., Englmann, I., \& Angerer, P. (2011). Cognitive demands and the relation between age and workload in apron control. Aviation Space and Environmental Medicine, 82, 26-33.
Müller, A., Weigl, M., Heiden, B., Glaser, J., \& Angerer, P. (2012). Promoting work ability and well-being in hospital nursing: The interplay of age, job control, and successful ageing strategies. WORK: A Journal of Prevention, Assessment \& Rehabilitation, 41, 5137-5144.

Ng, T. W. H., \& Feldman, D. C. (2008). The relationship of age to ten dimensions of job performance. Journal of Applied Psychology, 93, 392-423.

Podsakoff, P. M., MacKenzie, S. B., Lee, J. Y., \& Podsakoff, N. P. (2003). Common method biases in behavioral research: A critical review of the literature and recommended remedies. Journal of Applied Psychology, 88, 879-903.

R Development Core Team. (2013). R: A language and environment for statistical computing. Vienna, Austria: R Foundation for Statistical Computing.

Reijseger, G., Schaufeli, W. B., Peeters, M. C. W., Taris, T. W., van Beek, I., \& Ouweneel, E. (2013). Watching the paint dry at work: Psychometric examination of the Dutch boredoom scale. Anxiety, Stress \& Coping: An International Journal, 26, 508-525.

Rosseel, Y. (2012). lavaan: An R package for structural equation modeling. Journal of Statistical Software, 48, 1-36.

Rudolph, C. W., De Lange, A. H., \& Van der Heijden, B. I. J. M. (2015). Adjustment processes in bridge employment: Where we are and where we need to go. In P. M. Bal, D. T. A. M. Kooij, \& D. M. Rousseau (Eds.), Aging workers and the employee-employer relationship (pp. 221-242). New York, NY: Springer.

Salthouse, T. A. (1984). Effects of age and skill in typing. Journal of Experimental Psychology: General, 113, 345.

Salthouse, T. A. (2013). Within-cohort age-related differences in cognitive functioning. Psychological Science, 24, 123-130.

Schaie, K. W. (1994). The course of adult intellectual development. American Psychologist, 49, 304-313.

Schaie, K. W., \& Hofer, S. M. (2001). Longitudinal studies in aging research. In J. E. Birren, \& K. W. Schaie (Eds.), Handbook of the psychology of aging (5th ed., pp. 53-77). San Diego, CA: Academic Press.

Schalk, R., Van Veldhoven, M., De Lange, A. H., De Witte, H., Kraus, K., Stamov-Roßnagel, C., ... Zacher, H. (2010). Moving European research on work and aging forward: Overview and agenda. European Journal of Work and Organizational Psychology, 19, 76-101.

Schlick, C., Frieling, E., \& Wegge, J. (2013). Age-differentiated work systems. Berlin, Germany: Springer.

Shultz, K. S. (2003). Bridge employment: Work after retirement. In G. A. Adams, \& T. A. Beehr (Eds.), Retirement: Reasons, processes and results (pp. 214-241). New York, NY: Springer Publishing Company.

Shultz, K. S., \& Wang, M. (2011). Psychological perspectives on the changing nature of retirement. American Psychologist, 66, 170-179.

Shultz, K. S., Wang, M., Crimmins, E. M., \& Fisher, G. (2010). Age differences in the demand-control model of work stress: An examination of data from 15 European countries. Journal of Applied Gerontology, 29, 21-47.

Spector, E. (2006). Method variance in organizational research. Truth or urban legend? Organizational Research Methods, 9, 221-232.

Taris, T. W., \& Kompier, M. A. J. (2004). Job characteristics and learning behavior: Review and psychological mechanisms. In P. Perrewé 
and D. Ganster (Eds.), Research in occupational stress and well being: Exploring interpersonal dynamics (Vol. 4, pp. 127-166). Amsterdam, the Netherlands: JAI Press.

Taylor, M. A., \& Geldhauser, H. A. (2007). Low-income older workers. In K. S. Shultz, \& G. A. Adams (Eds.) Aging and work in the 21st century (pp. 25-49). Mahwah, NJ: Lawrence Erlbaum.

Topa, G., Moriano, J. A., Depolo, M., Alcover, C.-M., \& Moreno, A. (2011). Retirement and wealth relationships: Meta-analysis and SEM. Research on Aging, 33, 501-528.

Truxillo, D. M., Cadiz, D. M., Rineer, J. R., Zaniboni, S., \& Fraccaroli, F. (2012). A lifespan perspective on job design: Fitting the job and the worker to promote job satisfaction, engagement, and performance. Organizational Psychology Review, 2, 340-360.

Truxillo, D. M., \& Fraccaroli, F. (2013). Research themes on age and work: Introduction to the Special Issue. European Journal of Work and Organizational Psychology, 22, 249-252.

Van den Berg, T. I., Robroek, S. J., Plat, J. F., Koopmanschap, M. A., \& Burdorf, A. (2011). The importance of job control for workers with decreased work ability to remain productive at work. International Archives of Occupational and Environmental Health, 84, 705-712.

Van der Heijde, C. M. V. D., \& Van Der Heijden, B. I. J. M. (2006). A competence-based and multidimensional operationalization and measurement of employability. Human Resource Management, 45, 449-476.

Wang, M., Henkens, K., \& van Solinge, H. (2011). Retirement adjustment. A review of theoretical and empirical advancements. American Psychologist, 66, 204-213.

Wang, M., \& Shi, J. (2014). Psychological research on retirement. Annual Review of Psychology, 65, 209-233.
Wang, M., \& Shultz, K. S. (2010). Employee retirement: A review and recommendations for future investigations. Journal of Management, 36, 172-206.

Wang, M., Zhan, Y., Liu, S., \& Shultz, K. S. (2008). Antecedents of bridge employment: A longitudinal investigation. Journal of Applied Psychology, 93, 818-830.

Warr, P. (1993). In what circumstances does job performance vary with age? European Work and Organizational Psychologist, 3, 237-249.

Weigl, M., Müller, A., Hornung, S., Zacher, H., \& Angerer, P. (2013). The moderating effects of job control and selection, optimization, and compensation strategies on the age-work ability relationship. Journal of Organizational Behavior, 34, 607-628.

Westman, M., Hobfoll, S. E., Chen, S., Davidson, O. D., \& Laski, S. (2005). Organizational stress through the lens of conservation of resources (cor)theory. Research in Occupational Stress and Well Being, 4, 167-220.

Wöhrmann, A. M., Deller, J., \& Wang, M. (2013). Outcome expectations and work design characteristics in post-retirement work planning. Journal of Vocational Behavior, 83, 219-228.

Zacher, H., \& Frese, M. (2011). Maintaining a focus on opportunities at work: The interplay between age, job complexity, and the use of selection, optimization, and compensation strategies. Journal of Organizational Behavior, 32, 291-318.

Zaidi, A. (2010). Poverty risks for older people in EU countries-An update. Vienna, Austria: European Centre for Social Welfare Policy and Research.

Zhan, Y., Wang, M., Liu, S., \& Shultz, K. (2009). Bridge employment and retirees' health: A longitudinal investigation. Journal of Occupational Health Psychology, 14, 374-389. 